\title{
Summary of: Post-implant neuropathy of the trigeminal nerve. A case series.
}

\section{FULL PAPER DETAILS}

1*3-5King's College London Dental Institute, Besseme Road, London, SE5 9RS; ${ }^{2}$ Dawood \&t Tanner Dental Practice, 45 Wimpole Street, London, W1G 8SB ${ }^{*}$ Correspondence to: Professor Tara Renton Email: tara.renton@kcl.ac.uk; Tel 02032992313 Refereed Paper

Accepted 12 March 2012

DOI: 10.1038/sj.bdj.2012.497

'British Dental Journal 2012; 212: E17

\author{
T. Renton, ${ }^{1}$ A. Dawood, ${ }^{2}$ A. Shah, ${ }^{3}$ L. Searson ${ }^{4}$ and Z. Yilmaz ${ }^{5}$
}

Background The incidence of implant-related inferior alveolar nerve injuries (IANI) is steadily increasing within the UK population. Aims This study prospectively reviewed thirty cases (35\% male; 65\% female) of implant-related IANI seen in a specialist nerve injury clinic. Methods Neurosensory examinations were carried out to ascertain a quantifiable rating of the perception, pain profiling and functional difficulties. Data were analysed using SPSS software. Results Patients were aware of signing consent forms for the surgery in 11 cases and 8 of those felt they were not explicitly warned about nerve injury. Over $70 \%$ of patients were referred after six months post injury. Implant surgery planning involved intra-oral films only (30\%), CBCT (10\%), dental pantomograph (50\%) and long cone peri-apical radiographs (48\%). However, no radiographic evidence pre- or postoperatively was provided by the referring practitioner in 15\% of cases. Intra-operative problems included bleeding and neurological symptoms. Proximity of the implant bed or implant to the inferior alveolar canal was evident radiographically. This showed contact with roof inferior alveolar nerve canal in $44 \%$ of cases, protrusion into the canal in 20\% of cases, crossing of the canal in 20\% cases and distance in one case, presumed to be due to local anaesthetic injury. All patients presented with a demonstrable neuropathy, which included neuropathic pain (50\%) that interfered with speaking, kissing and socialising. Conclusions Consent, preoperative planning and appropriate referral were inadequate in provision of mandibular implants in this patient group. Recommendations have been proposed to improve practice and possible novel strategies are suggested for the prevention and improved management of these complications.

\section{EDITOR'S SUMMARY}

The overriding exhortation to us as professionals is to 'do no harm'. Inevitably in the course of human endeavour harm will be done but the most that we can aim for is that it happens as infrequently as possible.

The upsetting stories in this research paper occasioned on patients by avoidable injuries to the trigeminal/inferior alveolar nerve stand as a warning beacon to those of us who place implants or aspire to do so. The sad litany of poor planning, especially in terms of adequate radiographic images, questionable surgical technique and insufficient attention to post-operative detail and care deserve our immediate attention and especially those who offer teaching and training. Implants have made an overwhelmingly positive difference to the oral health and quality of life for so many in recent years that having the prospect of such benefit not only removed but actually made worse is little short of a tragedy for the patients involved, their families and colleagues.

One way in which the clinician can be helped to be reminded of potential dangers and risks is inherent in the process of gaining meaningful consent. Surely when one gets to the point of describing potential risks and consequences to the patient, the matter of nerve damage must be broached. The more alarming then to discover that many patients in this study did not recall the process of being counselled in this way and giving such consent. A further indictment.

The authors are to be commended on their study but also on the rehabilitative care they have been able to provide to the patients referred to them with these iatrogenic injuries. Good wishes should go with them in their expressed aim to gather nationwide data in an effort to help prevent further and future damage of the same sort.

The full paper can be accessed from the $B D J$ website (www.bdj.co.uk), under 'Research' in the table of contents for Volume 212 issue 11.

Stephen Hancocks Editor-in-Chief

DOI: 10.1038/sj.bdj.2012.495 
TO ACCESS THE BDJ WEBSITE TO READ THE FULL PAPER:

- BDA Members should go to www.bda.org.

- Click the 'login' button on the right-hand side and enter your BDA login details.

- Once you have logged in click the 'BDJ' tab to transfer to the BDJ website with full access.

IF YOUR LOGIN DETAILS DO NOT WORK:

- Get a password reminder: go to www.bda.org, click the login button on the right-hand side and then click the forgotten password link.

- Use a recommended browser: we recommend Microsoft Internet Explorer or Mozilla Firefox.

- Ensure that the security settings on your browser are set to recommended levels.

IF YOU HAVE NOT YET SIGNED UP TO USE THE BDA WEBSITE:

- Go to www.bda.org/getstarted for information on how to start using the BDA website.
IN BRIEF

- This paper highlights some of the risks of causing nerve injury during planning, preparation and placement of mandibular implants.

- Highlights potential pitfalls and problems.

- Provides tips on how to prevent these implant related trigeminal injuries.

\section{COMMENTARY}

Do you place implants in the posterior part of the lower jaw? How do you evaluate the risk of inferior alveolar nerve injury (IANI)? What do you tell patients are the consequences and if it occurs, how do you manage it?

Study of 30 patients with iatrogenic implant related nerve injury provides guidance which could reduce IAN injury related to implant surgery.

Planning implant placement requires adequate radiographic assessment and the leaving of a 'safety zone' between the implant and the IAN. It is salutatory that one third of patients suffering IANI in this cohort had only intra-oral radiographs. The required safety zone depends upon the skill of the operator, implant system and the accuracy of the radiographic examination; the suggested 2-4 $\mathrm{mm}$ is a sensible guide.

Disturbingly only 11 out of 30 patients were aware of signing a consent form and of those, 8 felt they were not explicitly warned about nerve injury. The degree to which these patients underwent a consensual process to agree their care is not known but their low level of perception of the process should be a marker to practioners to improve their overall engagement with the consent process. If an IANI occurs patients need know how to recognise it as prompt removal of the implant is required to prevent permanent injury (three patients in this study benefited from removal of the implant within 30 hours). Delay resulted in permanent disability and functional problems, reduced pleasure in kissing and affected speech for half the patients, while a third had problems with eating, drinking and brushing their teeth due to pain. Recurrent lip biting, dribbling and psychological problems were also reported.

Implant misplacement was the major aetiological cause of IANI with close proximity of the implants or the preparation bed to the inferior dental canal (25 out of 30). Other causes included injury related to an articaine mental block.

Intra-operative problems were experienced by $70 \%$ of patients - indications that an IANI could have occurred being excessive bleeding during drilling or pain, but also sensations such as tingling, hot water sensation on the chin and shooting pain.

Management of patients with a permanent IANI included: drugs such as anti-depressants, anti-epileptics or topical lidocaine patches and Botox injections, and counselling and cognitive behavioral therapy.

IANI have medico-legal implications with increasing costs and incidence.

The authors point out that other studies have shown that as many as a quarter of edentulous patients can present with a degree of altered IAN function prior to implant placement, posing the question: should we therefore be undertaking pre-operative neurosensory evaluation?

Ian Brook,

Professor of Oral Surgery

and Oral Medicine,

Director of Clinical Studies,

The University of Sheffield

\section{AUTHOR QUESTIONS AND ANSWERS}

1. Why did you undertake this research? We have established a national trigeminal nerve injury service at King's College Hospital. Over the last six years there has been a considerable increase in implant related nerve injuries which can be very debilitating for the patients. Traditionally nerve injury was predominantly caused by third molar surgery and LA injections, but more recently implants are becoming a more frequent cause. Trigeminal permanent nerve injury causes a lifetime of orofacial neuropathic pain for 70\% of patients and massively impacts on their quality of life. These injuries are very difficult to manage and many patients remain on chronic pain medication. This paper aimed to assess risk factors associated with these injuries and to evaluate potential management strategies to prevent and potentially reverse them.

\section{What would you like to do next in this area to follow on from this work?}

We would like to assess if the observations and recommendations from this work result in a decrease in referrals of patients with implant related nerve injury as all are preventable. A followup national audit of implantologists' experience of nerve injuries related to implants would confirm the actual temporary and permanent rates of injury. We will soon have a dedicated website for these injuries and hope that establishing a national audit reporting service will help us to better understand the actual incidence of this problem and improve prevention and management. 